\title{
Analysis of granular flow driven by a chain in horizontal pipes
}

\author{
学 福島 剛史（九工大院）正 富田 侑嗣（九工大）
}

Tsuyoshi FUKUSHIMA, Kyushu Institute of Technology, 1-1 Sensui-cho, Tobata-ku, Kitakyushu Yuji TOMITA, Kyushu Institute of Technology

Key Words : Numerical Simulation, Discrete Element Method, Three-Dimensional Analysis, Chain Conveyor, Granular Flow

\section{1 緒言}

粉粒体の輸送方法は多岐にわたる。その中でも機械的輸送 はもっとも古典的な輸送方法であり，現在においても主要な 位置を占める。チェーンコンベアは粒子層内に設置されたチ エーンの摩擦力と粒子間の内部摩擦を利用し，充填された粉 粒体を連続的に輸送する機械式コンベアであり，他のコンべ アと比較し，腐食性，摩耗性，粉粒体発應が少ない，占有面 積が少ないなどの優れた点を持つ。しかしながら，装置内の 粒子流動に関してはこれまでほとんど明らかにされておらず， 従来の研究(1)では操作条件を変化させて特性を評価するとい う試行錯誤的な実験方法をとらざるを得なかった.すなわち， 装置内で起きる現象はブラックボックス的に取り扱われ， 個々の粒子挙動の定量的な研究はほとんど行われていない.

そこで本研究では，水平輸送におけるチェーンコンベア内 の粒子運動を DEM（離散要素法）によって再現することを 目的とし，チェーンの移動速度と粒子挙動の関係を管内流動 の観察や流動状態の把握によって検討した。

2 計算手法

2-1 計算領域

計算領域を Fig.1(a)に示す. 内径 $D$, 管長 $l$ の円筒状領域 内に $2 \mathrm{~mm}$ の等間隔で駆動球体を配置し，チェーンコンベア の駆動チェーンと想定した. 球体の直径は $d_{c}=5 \mathrm{~mm}$ とした. $d_{p}=1.4 \mathrm{~mm}$ の被輸送粒子をランダムに配置させたのち, 重力 尼作用させて管底に滞留させる。これを本計算の初期粒子配 置とし，Fig.1(b)に示す。チェーンに任意の軸方向の速度を 与え，DEM を用いて各粒子の運動を運動方程式に基づき追 跡することにより，全体の粒子挙動をシミュレートした。粒 子に作用する接触力は，弾性接触理論に基づいた非線形モデ ルにより計算した。本計算では取り扱う粒子数を减じるため, 管の上流および下流境界に周期境界条件を用いて，十分長い 水平管の一部分として表現した。また，局所粒子速度の評価 のための検査体積として，Fig.1(b)に示寸ように被輸送粒子 がほぼ 6 個含まれるように管中央部から横方向に幅 $b$ の領域 をとった。

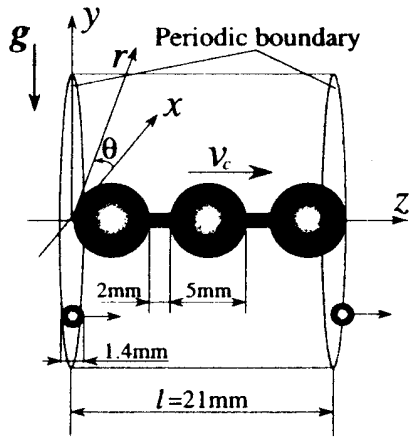

(a)

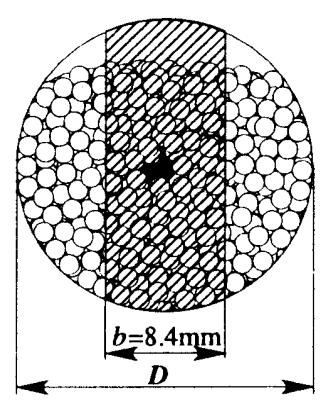

(b)
Fig.1 (a) Calculation area and coordinates.

(b) Initial distribution of particles and calculation area.

\section{2-2 計算条珄}

計算条件を Table 1 に示す，粒子は付着性を考慮せず，プ ラスチックと同様の物性值を採用した。粒子と壁面の摩擦係 数は等しくとった。なお，装置内の空気の影響は粒子の慣性 に比心゙て小さいために無視した。総計算時間を 8 秒間とし, 局所粒子速度, 局所粒子体積率, 輸送量は粒子流動が定常之 なる計算開始より 5 秒後から算出した.

\section{Table 1 Condition of calculation.}

\begin{tabular}{|c|c|c|}
\hline Pipe diameter [mm] & 20 & 30 \\
\hline Time step [s] & \multicolumn{2}{|c|}{$1.0 \times 10^{-4}$} \\
\hline Particle number & 2122 & 4893 \\
\hline Initial solid fraction & 0.476 & 0.479 \\
\hline Poisson's ratio & \multicolumn{2}{|c|}{0.3} \\
\hline Modulus of elasticity $\left[\mathrm{N} / \mathrm{m}^{2}\right]$ & \multicolumn{2}{|c|}{$1.0 \times 10^{5}$} \\
\hline Friction coefficient & \multicolumn{2}{|c|}{0.26} \\
\hline Particle density $\left[\mathrm{kg} / \mathrm{m}^{3}\right]$ & \multicolumn{2}{|c|}{1670} \\
\hline
\end{tabular}

\section{3 計算結果}

\section{3-1 粒子流動の観察}

Fig.2にパイプ内径 $D=20 \mathrm{~mm}, 30 \mathrm{~mm}$ におうる計算開始後 7.95 秒から 0.005 秒毎の管軸鉛直断面での粒子流動を示す. 各図 において，粒子流動の追跡を容易にするため，観察開始時に 特定の場所の被輸送粒子，チェーンに見立てた剾動軸と駆動 球体を着色した。このような粒子流動を実験等で見ることは 実際にはかなり困難と思われる。

図より被渝送粒子はチェーンと被輸送粒子の速度差により 生じるせん断力に加えて，チェーンの凹凸に粒子が掻き込ま れて輸送されることがわかる。粒子流動はチェーンを境に上 下 2 つに分れる.チェーンより上部に存在する粒子はチェー ンに乗せられた状態で輸送される。一方，チェーンより下部 の粒子はせん断流れが主要な殹動力となる.この 2 つの流れ はチェーン速度 $v_{c}$ によって流動状態が変化する． $v_{c}$ が十分低 い場合，軸対称的なせん断流れを形成する， $v_{c}$ が上昇すると， 上部の粒子は管内を跳躍しながら進行し，下部の粒子はチェ ーンの凹凸に入り込むことが困難となり，チェーンより下部 における輸送領域が狭まっていく傾向が確認された。全体の 傾向としてチェーンがある一定以上の速度に達すると被輸送 粒子との間に滑りが生じ，輸送能力に限界が生ずることが考 えられる．パイプ内径が増大すると，粒子速度は堿少する傾 向が見られ，同速度においても渝送形態が変化することが確 認された。これは壁面と粒子，粒子と粒子の相互摩擦の状況 の変化によるものであり，チェーンコンベアの持つ特徵 ${ }^{(2)}$ と も一致する傾向にある。詳細については実呀による定量的評 価を得るなどして，今後の課題としたい．以上より，2つの 輸送領域が存在し，最適なチェーン速度やパイプ内径が存在 することが確認された。

\section{3-2 粒子速度，粒子体積率，輸送量}

Fig.3 に局所粒子速度, Fig.4 に局所粒子体積率，Fig.5 に 輸送量を示す. 各図において, open symbol が $D=20 \mathrm{~mm}$, closed symbol が $D=30 \mathrm{~mm}$ における結果を示す. Fig.3 により， $v_{c}$ の 增加による粒子速度の増加は一定の值でピークをとり，それ 以上では減少，飽和する傾向が明らかとなった。また，チェ ーンより下部の輸送領域が $v_{c}$ によって異なり， $v_{c}$ の低いほう が広くなる傾向を示す。このため，Fig.2(b)，Fig.2(c)におけ る粒子速度のピークはほぼ同じ值を持つが, 輸送領域が異な るために輸送量に大きな差違が生じる．Fig.2(d)においては チェーンより下部の領域ではほとんど輸送がみられず，管上 部を跳躍していることが確認される。なお，それぞれの管底 部において粒子濃度が低いのは壁面-粒子の接触をしている ため，粒子-粒子の接触のように粒子が入り込む間隙が無い ためである

Fig.5 で示すように輸送量は粒子速度と同じくピークを持 ち， $v_{c}$ の増加によって减少，飽和する傾向を持つ，パイプ内 
径の増大については前節 3-1で述べたように，粒子速度に対 して堿少の影響を及ぼすが，他方，Fig.4より明らかなよう にチェーンより下部の領域は粒子浱度が密であるので，輸送 量は大きくなる

\section{3-3 伝達率}

Fig.6 はロープにかかる動力と粒子の仕事率の比を示した ものであり，次式で算出した。

$$
\eta=\frac{\sum_{m=1}^{n}\left[F_{r \times} v_{r=x}\right]}{\sum_{n=1}^{k}\left[F_{c x} v_{c s}\right]} \times 100 \quad[\%]
$$

ここで， $F_{c z} F_{p z}$ はチェーンと粒子にかかる駆動軸方向の力, $v_{c a} v_{p 2}$ はチェーンと粒子の駆動軸方向速度， $k$ は駆動粒子数， h!被輸送粒子数である。｜（はパイプ内径が小さい方が大き い。これはチェーンから粒子に伝わる力の割合が大きいこと を示している， $v_{c}$ が高い場合， $\eta$ が下がるのは前節 3-1 で 述べたように，チェーン，粒子間における滑りのため力が効 果的に伝達されないことと，被輸送粒子が擋汼されながら輸 送されるため，速度べクトルの方向が著しく変化することな どが考えられる。以上の結果より，輸送形態としては滑りの 発生しない速度領域で使用することが望ましいと言える。

4 結言

本研究では水平輸送のチェーンコンベアにおける粒子輸送 の数値シミュレーションによって，アプローチの困難である 流動状態の把握，粒子流動分布の解析を試みた。その結果と して, 流動状態の変化による喻送量の変化, 各パラメータに おけるピークの存在等，実際の現象と同様の結果が見られ， 内部流動に関する知見を得ることができた。

参考文献

(1) Madhusudana Rao und G.Raman, fördern und heben, 24 (1974) Nr.7, 697-704.

(2) 粉粒体の輸送,化学工業社,(1988), 174-180

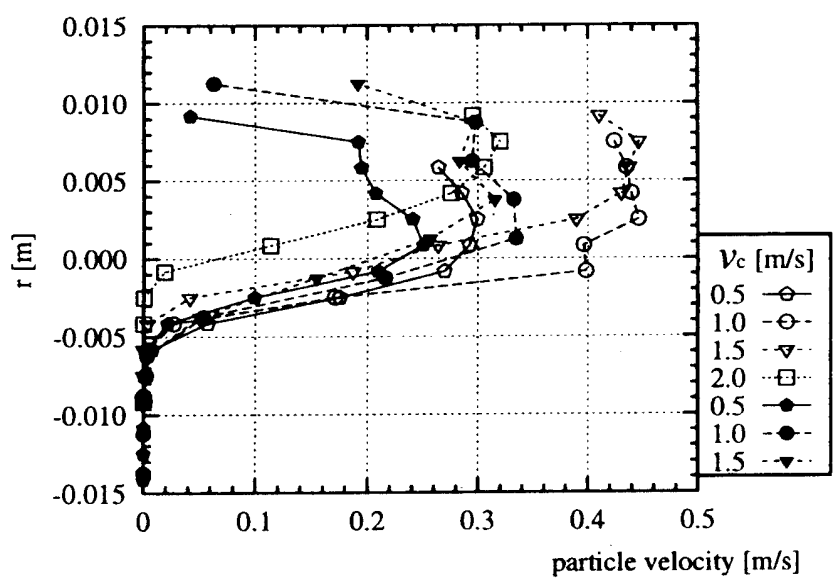

Fig.3 Axial velocity distribution of particles, open symbol : $D=20 \mathrm{~mm}$, closed symbol : $D=30 \mathrm{~mm}$.

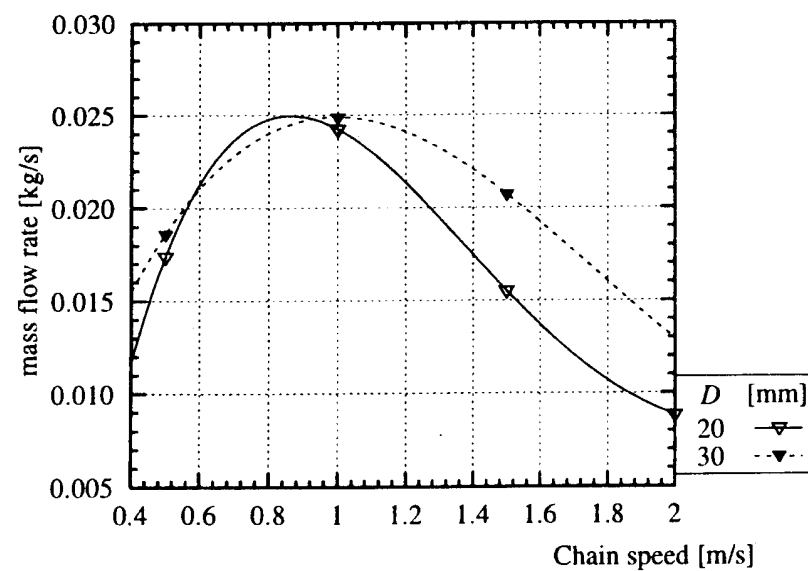

Fig.5 Relationship between mass flow rate and chain speed, open symbol : $D=20 \mathrm{~mm}$, closed symbol : $D=30 \mathrm{~mm}$. (a)
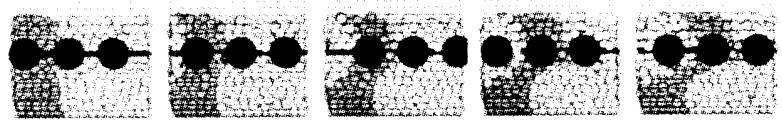

(b)
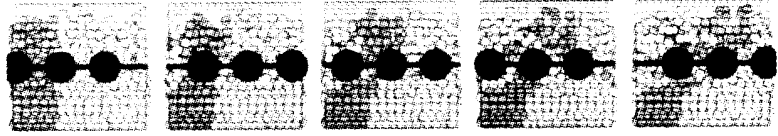

(c)
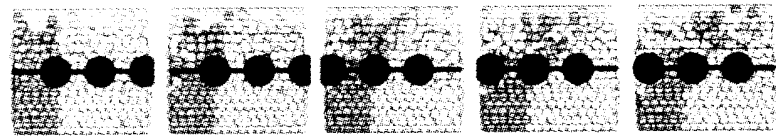

(d)
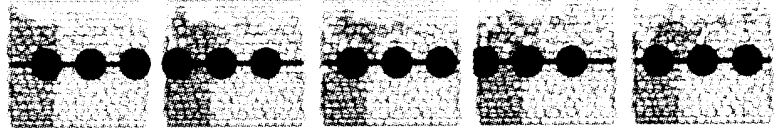

(e)
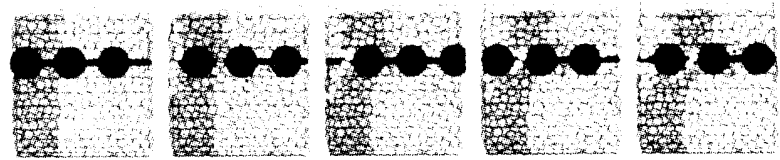

(f)
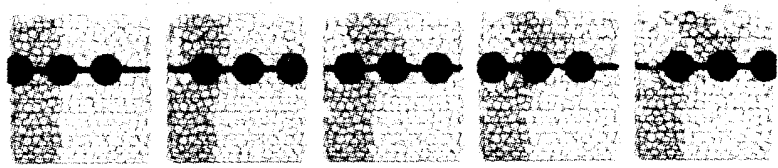

Fig.2 Snapshot of particle flow during 7.95 [s] 7.97 [s] [every 0.005s].
$D=20[\mathrm{~mm}]$ :
(a) $: v_{\mathrm{c}}=0.5[\mathrm{~m} / \mathrm{s}]$
(b) $: v_{\mathrm{c}}=1.0[\mathrm{~m} / \mathrm{s}]$
(c) $: v_{\mathrm{c}}=1.5[\mathrm{~m} / \mathrm{s}]$
(d) $: v_{\mathrm{c}}=2.0[\mathrm{~m} / \mathrm{s}]$
$D=30[\mathrm{~mm}]$ :
(e) $: v_{c}=0.5[\mathrm{~m} / \mathrm{s}]$
(f) $: v_{\mathrm{c}}=1.0[\mathrm{~m} / \mathrm{s}]$

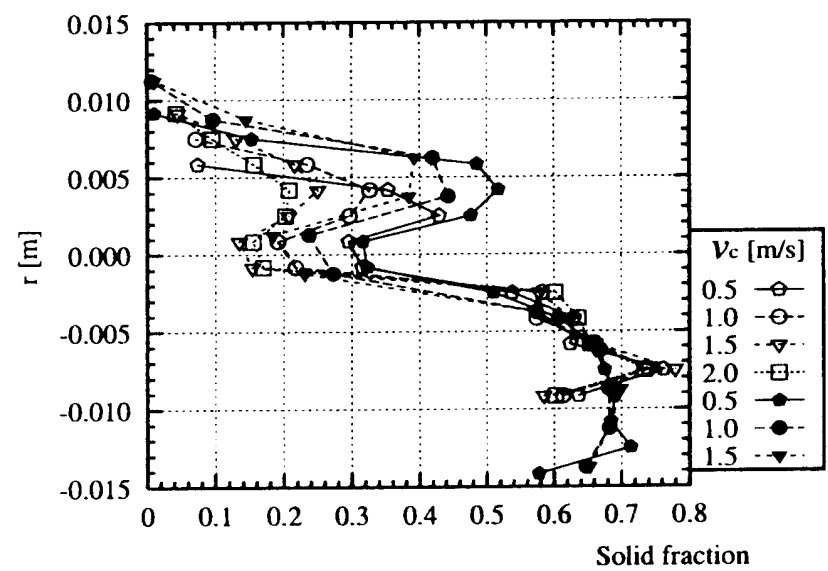

Fig.4 Solid fraction,

open symbol : $D=20 \mathrm{~mm}$, closed symbol : $D=30 \mathrm{~mm}$.

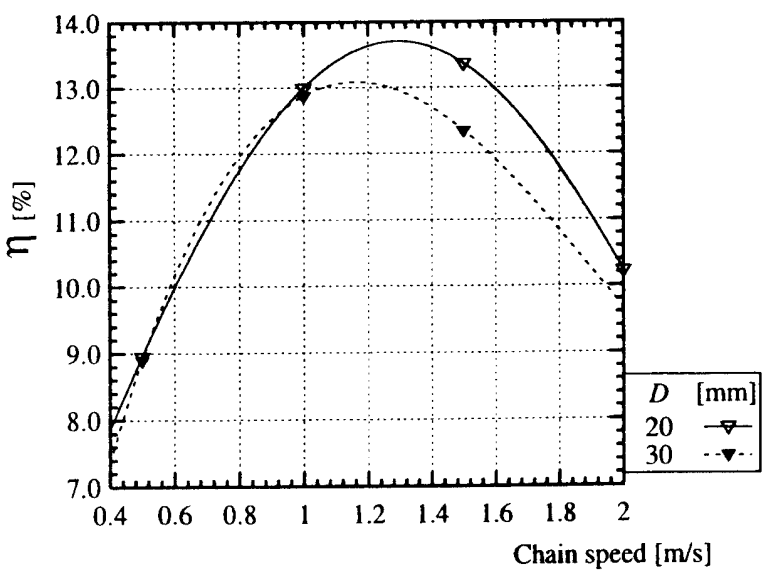

Fig.6 Efficiency,

open symbol : $D=20 \mathrm{~mm}$, closed symbol : $D=30 \mathrm{~mm}$. 